\title{
Early Complications of Arteriovenous Fistula in patients on maintenance Hemodialysis
}

MUHAMMAD ASIF ${ }^{1}$, FAIZA SIDDIQUE ${ }^{2}$, ANUM AWAIS ${ }^{3}$, USMAN SIDDIQUE ${ }^{4}$, ABRAR-UL-HASSAN PIRZADA $^{5}$, RABIA

SAEED ${ }^{6}$, HUMAIRA ALAM ${ }^{7}$, AHSEN NAZIR AHMED ${ }^{8}$

${ }^{1}$ Associate Prof of Urology ,Azra Naheed Medical College, Lahore

${ }^{2}$ Consultant General surgeon, king khalid General hospital, Hafar Al Batin, KSA

${ }^{3}$ Senior Registrar of Radiology, University of Lahore Teaching Hospital

${ }^{4}$ Senior Registrar, General Surgery, Mayo Hospital Lahore.

${ }^{5}$ Assistant Prof of Plastic Surgery, Azra Naheed Medical College, Lahore

${ }^{6}$ Senior Registrar, Deptt of Surgery, Lahore General Hospital

${ }^{7}$ Assistant Prof of Surgery, Azra Naheed Medical College, Lahore

${ }^{7}$ Professor of Surgery, Azra Naheed Medical College, Lahore

Correspondence to Dr. Muhammad Asif, drasifbaloch@yahoo.com . Contact No. 03314845145

\begin{abstract}
Background: Repeated access to circulation is essential to conduct the adequate maintenance hemodialysis. The efficiency of arteriovenous fistula, being permanent source of access to vascular system in hemodialysis, is severely hampered by its complications

Aim: To determine the frequency of most common early complications of arteriovenous fistula in patients on maintenance hemodialysis.

Methods: This cross sectional study was conducted over a period of five years. Total 450 patients of hemodialysis were included. Informed consent was taken and demographics were noted. Early postoperative complications of AV fistula were recorded.

Results: Average age of the patients was $39.61 \pm 8.17$ years. There were $255(56.7 \%)$ males and $195(43.3 \%)$ females. Radiocephalic fistula was constructed in 198 (44\%) cases while brachiocephalic fistula in $252(56 \%)$ cases. Among early complications, 19 (4.2\%) cases had wound infection, $27(6 \%)$ had thrombosed AV accesses and $12(2.6 \%)$ had bleeding.

Conclusion: Early complications of AVF may compromise its efficacy as source of vascular access for maintenance hemodialysis. Timey detection and management improves patient morbidity.

Keywords: Maintenance Hemodialysis, Arteriovenous fistula, Infection, Thrombosis, Bleeding.
\end{abstract}

\section{INTRODUCTION}

Chronic kidney disease (CKD) and end-stage renal disease(ESRD) are the global health problems worldwide. The prevalence ofCKD varies by region, ranging from $7 \%$ to $24 \%$ worldwide. ${ }^{1}$ In Pakistan, The prevalence of CKD in Pakistan is $16.6 \%-25 \%$. Patients with CKD are commonly diagnosed at a late stage due to poor health education, scarcity of health facilities as well as late diagnosis of predisposing factor like hypertension and diabetes mellitus ${ }^{2,3}$. Patients presenting in advanced stages of CKD or ESRD can't be offered any treatment to reverse or slow down progression. These patients are the candidates of renal replacement therapy either dialysis or renal transplant. ${ }^{2}$

Hemodialysis is one of the ways of renal replacement therapy that requires repeated vascular access two to three times a week through AVF (AVF) created on one of the upper limbs. ${ }^{5}$ It has become a necessary evil in the management of ESRD. Patient survival is upto 6 months if hemodialysis is not done in ESRD. ${ }^{2}$ However it has its own side effects that limit its efficiency. Patients have the fear of needles. Repeated visits to hospitals affect the social and economic status of the patient. ${ }^{1,5}$ Thesepatients develop systemic as well as local complications including cardiovascular diseases, infections, and malignant

Received on 07-01-2021

Accepted on 27-05-2021 neoplasms and have a very poor prognosis as the mortality 3 years after the initiation of dialysis exceeds $30 \%{ }^{1,6}$ Similarly local complications related to management of AVF are very cumbersome.Infection of AVF needs management by intravenous (IV) antibiotics, drainage of abscess and closure of fistula. Thrombosis of AVF leads to permanent loss of IV access. Similarly bleeding, ischemic steal syndrome and pseudoaneurysm of AVF may need secondary intervention and revision of fistula. Thus dysfunction of fistulas is the most common reason for recurrent hospitalization and increased morbidity. ${ }^{7,8}$ These problems are more pronounced in resource poor countries due to their poor socioeconomic status. ${ }^{2}$

This study focuses on the knowledge of complications of AVF in our set up. In Pakistan, lack of a central registry makes epidemiological assessment extremely difficult and inadequate. Most of the data regarding disease burden estimates are mostly center-based. ${ }^{3}$ So the aim of this study is to determine the frequency of most common complications of atrioventricular fistula in chronic renal failure patients on maintenance hemodialysisto get information regarding extent of problem in local setting and efficiency of AVF in patients of chronic renal failure.

The objective of the study was to determine the frequency of most common complications of arteriovenous fistula in patients on maintenance hemodialysis 


\section{MATERIALS AND METHODS}

This cross sectional study was conducted from January 2014 to December 2029. Sample size was 450 using anticipated proportion $=7 \%, 95 \%$ confidence interval and $2.5 \%$ margin of error. Sampling technique used was non Probability (Consecutive) Sampling. Patients aged 1565years, of both genders presenting with chronic renal failure with creatinine $>2 \mathrm{mg} / \mathrm{dl}$ and $\mathrm{eGFR}<30$, undergoing hemodialysis for $>6$ months though atrioventricular fistula were included in the study. Patients with brachiocephalic fistula, in which fistula were constructed at the antecubital fossa or radiocephalic fistula, in which fistula were constructed at the wrist were included. Patients already diagnosed with cardiovascular disease or taking immunosuppressive medications, having malignancy, procoagulant conditions, or patients in whom graft material was used were excluded from the study.

Data Collection: The study was conducted after approval from hospitals research and ethical board. All patients fulfilled inclusion criteria were enrolled in the study through nephrology ward. A written informed consent was obtained from all patients. Medical history was taken from each patients including diabetes and hypertension and duration of hemodialysis. All patients underwent chronic hemodialysis for a mean time of 4.0hours three times a week. Blood flow rate ranged $250-300 \mathrm{~mL} / \mathrm{min}$, whereas a dialysate flow rate of $500 \mathrm{~mL} / \mathrm{min}$ was used. Then patients were evaluated at fistula site and early complications within 4 to 6 weeks of AVF creation were noted. The complications were wound infection, thrombosed AV accesses and bleeding. All data were stored and analyzed in SPSS version 21.0.

\section{RESULTS}

Average age of the patients was $39.61 \pm 8.17$ years. There were $255(56.7 \%)$ males and $195(43.3 \%)$ females. There were $165(36.7 \%)$ diabetics, 75 (16.7\%) had hypertension while $210(46.7 \%)$ patients had both diabetes and hypertension. Radiocephalic fistula was used in 198 (44\%) cases while bronchiocephalic fistula in 252 (56\%) cases. The mean maturation time of Radiocephalic fistula was $42.42 \pm 4.45$ days while mean maturation time of bronchiocephalic fistula was $38.23 \pm 4.54$ days $(p<0.05)$ (Table 1). Among early complications, 19 (4.2\%) cases had wound infection, 27 (6\%) had thrombosed AV accesses and $12(2.6 \%)$ had bleeding Table 2

Table 1: Demographics of patients $(n=450)$

\begin{tabular}{|l|l|}
\hline Age & $39.61 \pm 8.17$ \\
\hline Gender (M:F) & $255(56.7 \%): 195(43.3 \%)$ \\
\hline Comorbidities & $165(36.7 \%)$ \\
\hline Diabetes & $75(16.7 \%)$ \\
\hline Hypertension & $210(46.7 \%)$ \\
\hline Diabetes+ hypertension & $198(44 \%)$ \\
\hline Radiocephalic fistula & $252(56 \%)$ \\
\hline Bronchiocephalic fistula &
\end{tabular}

Table 2. Type of complications

\begin{tabular}{|l|c|}
\hline Early complications & $\mathbf{n}$ \\
\hline Total & $58(12.9 \%)$ \\
\hline Wound infection & $19(4.2 \%)$ \\
\hline Thrombosed AV accesses & $27(6 \%)$ \\
\hline Bleeding & $12(2.6 \%)$ \\
\hline
\end{tabular}

\section{DISCUSSION}

The ESRD is multifactorial with hypertension and diabetes being the major risk factors worldwide. ${ }^{1}$ The prevalence of diabetes and hypertension varies among ESRD with hypertension being the leading cause in most of the studies. $1,9,10$ In our study, diabetes was leading factor of CRF $(36.7 \%)$ than hypertension $(16.7 \%)$ which contradicts most of the international statistics and western data. However this is in agreement with a Pakistani study, in which common causes of renal failure identified were diabetic nephropathy (28\%) and hypertension (14.6\%). ${ }^{3}$ another study by Demiral S et.al, DM was found in $43.2 \%$ patients and hypertension was found in $13.2 \%$ patients. ${ }^{7}$ this difference is due to variable disease burden in different parts of the world with DM being the leading cause of ESRD in Indian subcontinenet and Hypertension in the western countries. ${ }^{3}$

The preferred site of AVF is radiocephalic followed by brachiocephalic fistula, ${ }^{7}$ however in patients with DM and peripheral vascular disease, brachiocephalic fistula is preferred to avoid complications related to vascular access and maintenance of fistula. ${ }^{7}$ As most of the patients in our study were diabetic with deficiency of peripheral venous structures, brachiocephalic fistula was preferably constructed in majority of the patients $(56 \%)$ to avoid its complicatins.

Thrombosis is among the common early and late complications in AV fistulas that may lead to loss of vascular access. ${ }^{8,9,11,12}$ It occurs at the site of stenosis in AVF and may cause inflow and outflow obstruction. ${ }^{12}$ In our study it was repoted to be $6 \%$. In a study by Salahiet. al showing $2.2 \%$ patients were reported to have thrombosis ${ }^{12}$.

Infection accounts for majority of local as well as systemic AVF complications, ${ }^{13}$ Most AVF infections involve perivascular cellulitis, which manifests as localized erythema and edema and is usually easily treated. Much more serious is an infection associated with anatomical abnormalities, such as aneurysms, hematomas or abscesses, which require surgical excision and drainage. ${ }^{13}$ Infection rate in our study was $4.5 \%$. Another study by Johny $S$ et.al showed comparable infection rates of $3.4 \% .{ }^{12}$ Salahi et al reported relatively lower infection rates $0.5 \%{ }^{11}$ while Thabet $23.8 \%$ reported very high infection rate. ${ }^{6}$

Bleeding was another early complication and was founmd in $2.6 \%$ patients in our study. Similar rates of bleeding and hematoma formation were noted in study by Johny $S$ et al. the rate of bleeding was low in Salahi et al $0.5 \%{ }^{11}$. 
Overall, variability in complication rates had been observed, partly due to poor quality studies, significant heterogeneity of study populations, and inconsistent definitions. There is an urgent need to standardize reporting of methods and definitions of vascular access complications in future clinical studies to better inform patient and provider decision making. ${ }^{11}$

\section{CONCLUSION}

A functional AVF is a major determinant of successful HD; however, a complicated AVF may become a potential risk leading to morbidity and mortality of the patients on HD. Knowing the various complications of AVF helps the health care professional in their early detection and timely management,thus contributing significantly to reduce patient hospitalization, recurrent surgical interventions and loss of AVF.

\section{REFERENCES}

1. Nath JD, Kashem A. Etiology and frequency of hospital admissions in maintenance hemodialysis patients in chronic kidney disease. Saudi J Kidney Dis Transpl [serial online] 2019 [cited 2020 Feb 17];30:508-12. Available from: http://www.sjkdt.org/text.asp?2019/30/2/508/256858

2. Shafi ST, Saleem M, Anjum R, Abdullah W, Shafi T. Refusal of hemodialysis by hospitalized chronic kidney disease patients in Pakistan. Saudi Journal of Kidney Diseases and Transplantation. 2018 Mar 1;29(2):401.

3. Ullah K, Butt G, Masroor I, Kanwal K, Kifayat F. Epidemiology of chronic kidney disease in a Pakistani population. Saudi Journal of Kidney Diseases and Transplantation [Letter to the Editor] 2015 November 1, 2015;26(6):1307-10.
4. Imtiaz S, Salman B, Qureshi R, Drohlia M, Ahmad A. A review of the epidemiology of chronic kidney disease in Pakistan: A global and regional perspective. Saudi Journal of Kidney

5. Thabet BAE-H, Ewas MO, Hassan HA, Kamel MN. Complications of AVF in dialysis patients at Assiut University Hospital. Journal of Current Medical Research and Practice 2017;2(2):119

6. Yamagata K, Hoshino J, Sugiyama $H$, Hanafusa N, Shibagaki $\mathrm{Y}$, Komatsu $\mathrm{Y}$, et al. Clinical practice guideline for renal rehabilitation: systematic reviews and recommendations of exercise therapies in patients with kidney diseases. Renal Replacement Therapy 2019 2019/06/13;5(1):28.

7. Demiral S, Turkoglu O, Turkoglu Z. Complications of AVF Created for Hemodialysis Access and Treatment Approaches. Eurasian J Med Oncol;1(2):76-81.

8. Al-Jaishi AA, Liu AR, Lok CE, Zhang JC, Moist LM. Complications of the AVF: a systematic review. Journal of the American Society of Nephrology 2017;28(6):1839-50.

9. Ghonemy TA, Farag SE, Soliman SA, El-Okely A, El-Hendy $Y$. Epidemiology and risk factors of chronic kidney disease in the El-Sharkia Governorate, Egypt. Saudi Journal of Kidney Diseases and Transplantation 2016;27(1):111.

10. Afifi WM, Elsaoud AMA, Elgawish MH, Ghorab AM. Musculoskeletal manifestations in end-stage renal disease patients on hemodialysis and relation to parathyroid dysfunction. Saudi Journal of Kidney Diseases and Transplantation 2019;30(1):68.

11. Salahi H, Fazelzadeh A, Mehdizadeh A, Razmkon A, MalekHosseini S-A, editors. Complications of AVF in dialysis patients. Transplantation proceedings; 2006: Elsevier.

12. Johny S, Pawar B. Complications of AVF for haemodialysis access. International Surgery Journal 2018;5(2):439-44.

13. Saxena AK, Panhotra B, Al-Mulhim AS. Vascular access related infections in hemodialysis patients. Saudi Journal of Kidney Diseases and Transplantation 2005;16(1):46. 